\title{
Pathways toward Peace: Negotiating National Unity and Ethnic Diversity through Education in Botswana
}

\section{Citation}

Dryden-Peterson, S. and Bethany Mulimbi. 2017. Pathways Toward Peace: Negotiating National Unity and Ethnic Diversity through Education in Botswana. Comparative Education Review 61 (1) (February): 58-82.

\section{Published Version}

doi:10.1086/689614

\section{Permanent link}

http://nrs.harvard.edu/urn-3:HUL.InstRepos:30194042

\section{Terms of Use}

This article was downloaded from Harvard University's DASH repository, and is made available under the terms and conditions applicable to Open Access Policy Articles, as set forth at http:// nrs.harvard.edu/urn-3:HUL.InstRepos:dash.current.terms-of-use\#OAP

\section{Share Your Story}

The Harvard community has made this article openly available.

Please share how this access benefits you. Submit a story.

\section{Accessibility}




\title{
Pathways Toward Peace?
}

\section{Negotiating National Unity and Ethnic Diversity through Education in Botswana}

\author{
Sarah Dryden-Peterson, Harvard Graduate School of Education \\ Bethany Mulimbi, Harvard Graduate School of Education
}

Corresponding Author:

Sarah Dryden-Peterson

Harvard Graduate School of Education

6 Appian Way

Gutman Library 457

Cambridge, MA 02138 USA

Tel: 617-495-8162/ 617-435-2344

Email: sarah_dryden-peterson@gse.harvard.edu

\section{Acknowledgements}

We express our thanks to colleagues at the University of Botswana, especially Owen Pansiri and Lydia Nyati-Saleshando; to Pierre de Galbert for research assistance; and to Elisabeth King, Julia Paulson, and the Cultures and Institutions Colloquium at the Harvard Graduate School of Education for feedback on earlier drafts. The study was generously funded by the Weatherhead Center for International Affairs at Harvard University. All errors or omissions are our own. 


\title{
Pathways Toward Peace:
}

\section{Negotiating National Unity and Ethnic Diversity through Education in Botswana}

\begin{abstract}
This study examines how education can disrupt threats of conflict, specifically in the presence of ethnic diversity. We present a historical analysis of Botswana, using methods of process tracing drawing on documents, in-depth interviews, and Afrobarometer survey data. Post-independence Botswana engaged in redistribution of educational access across ethnic groups and promotion of common civic principles of social harmony. At the same time, it constructed through schools ethnically-based national identity, which excluded many minorities. Lack of recognition for ethnic minorities remains a persistent challenge, yet it exists in a context of high commitment to unity and the nation-state, even among minority groups, which may have allowed recent dissent to happen peacefully. The paper defines mechanisms by which educational redistribution and recognition can disrupt resource-based and identity-based inequalities that often lead to conflict. This model holds promise for conflict avoidance and mitigation in multiethnic states globally.
\end{abstract}




\section{Pathways Toward Peace:}

\section{Negotiating National Unity and Ethnic Diversity through Education in Botswana}

Botswana has been celebrated as an example of enduring peace (Acemoglu and Robinson 2012, 404-414), while many postcolonial Sub-Saharan African nations have struggled with ongoing armed conflict. Since independence in 1966, it has remained the most peaceful country on the African continent, ranking 31 out of 162 countries on the Global Peace Index (Institute for Economics and Peace 2015, 8). It has achieved this stability despite one of the most salient predictors of conflict: high ethnic diversity with one ethnic group numerically dominant (Alesina et al. 2003; Collier 2001; Eifert, Miguel, and Posner 2010).

How has Botswana charted a pathway toward peace in spite of the existence of ethnic diversity? In this article, we build on the work of scholars who argue that it is not the presence of ethnic diversity alone that predicts conflict but instead how this diversity is mobilized by institutions and policies of the state (Fearon 2003; Habyarimana et al. 2008).

Many studies document how the state mobilized ethnic diversity toward conflict in, for example, Rwanda, Nepal, Sierra Leone, Lebanon, and Yugoslavia (see, for example, King 2014; Novelli and Smith 2011; Heyneman 2000). Underexplored are the ways states can prevent and mitigate conflict in the presence of ethnic diversity, particularly through education (Davies 2011; Bush and Saltarelli 2000).

Botswana's "exceptionalism” has been explained by the economic wealth generated through diamond revenues. We argue that the ways in which Botswana has negotiated national unity and ethnic diversity are equally exceptional. We examine this instructive negotiation through analysis of education in Botswana from independence in 1966 to the present. We take 
this approach, given the conjunction of (1) the propensity for formal, mass education to be a central means of constructing and conveying notions of national identity (Smith 1991); and (2) the significant association between armed conflict and exclusionary conceptions of national identity forwarded in schools (Davies 2011; King 2014). Importantly, Botswana's early leaders regarded the formal education system as "potentially the most important single instrument for nation-building" (National Commission on Education (NCE) 1977, 12).

In the next section, we explore how Botswana might have followed a pathway toward conflict, especially given its ethnic diversity. In the conceptual framework that follows, we define how resource-based and identity-based inequalities contribute to conflict and the mechanisms by which educational redistribution and recognition might disrupt these inequalities. After outlining our historical process-tracing research design, we present analysis of four "historical moments," which define critical periods of negotiation between national unity and ethnic diversity. In the final section, we return to a discussion of the conceptual dilemma of building national unity in the presence of ethnic diversity and discuss lessons from Botswana for other multiethnic education systems as well as for Botswana's own future.

\section{The Possibility of Conflict in Botswana}

Conflict in Botswana was more probable than peace. At independence, Botswana was among the poorest and least educated countries in the world (Gulbrandsen 2012, 255), and it was surrounded by countries experiencing armed conflict in the form of civil wars - in Angola, Mozambique, and Zimbabwe - and ongoing racial strife - in South Africa and Namibia. Further, Botswana exemplified many of the same predictors of conflict: an economy based on natural resources (Acemoglu and Robinson 2012; Collier and Hoeffler 2004); low levels of education 
(Shields and Paulson 2014); and high ethnic diversity with one ethnic group numerically dominant (Alesina et al. 2003; Collier 2001; Eifert, Miguel, and Posner 2010).

The infusion of democratic principles into post-independence institutions led to vesting the wealth of diamonds in the state in lieu of in tribes or corporations (Acemoglu and Robinson 2012; Gulbrandsen 2012), countering the first predictor of conflict. For example, education spending as a percentage of Gross Domestic Product (GDP) has been consistently close to 10 percent in Botswana over the past two decades, among the highest in the world (World Bank 2015). This redistribution of diamond wealth acted on the second predictor of conflict: low levels of education. Botswana's leaders have invested heavily in public education since 1966, at which time just 20 percent of children were enrolled in primary school; only 8 percent made the transition to secondary school; among all its citizens, Botswana counted just 100 secondary school graduates (Acemoglu and Robinson 2012); and there were no universities in the country (Meyer, Nagel, and Snyder 1993, 456). Thirty years later, in 1996, 96 percent of school-age children were enrolled in school. This expansion in access to education mirrors later trends across the world, yet Botswana had achieved near universal primary education by the time of the Education for All meetings in Dakar in 1990. Almost fifty years after independence, a child born in Botswana could expect 12.4 years of education, the highest in sub-Saharan Africa (UNESCO 2011).

Governance-focused explanations of Botswana's stability have over-looked the third predictor of conflict: the presence of ethnic diversity. Many scholars have argued that "Botswana has one of the most ethnically homogeneous populations in Africa" (Alesina et al. 2003, 181). Given that high ethnic diversity is associated with conflict, this homogeneous characterization of the country helps to explain the lack of conflict. Yet, this generalization misrepresents ethnic 
realities in Botswana (Boikhutso and Jotia 2013; Nyati-Ramahobo 2006; Werbner 2002; Fearon 2003). In fact, Botswana is ethnically heterogeneous, with a pattern of diversity that is most predictive of conflict: one dominant ethnic group with many minority groups.

Although the name of the country indicates that Botswana is the home of the Batswana people, many ethnic groups reside within its borders. The Constitution of Botswana recognizes eight "major tribes" who are sometimes considered separate ethnic groups but share the common language, Setswana (Nyati-Ramahobo 2006; Pansiri 2012; Republic of Botswana 2000). These groups, living mainly in the south and east of Botswana, are the Bangwato, Bangwaketse, Bakgatla, Balete, Batlokwa, Batawana, Barolong, and Bakwena. In this paper, as is customary in English, we refer to these ethnic groups as Tswana and to their language as Setswana, reserving the term 'Batswana' to connote citizens of Botswana, regardless of ethnic origin. Tswana are the numerically dominant ethnic group in Botswana, yet estimates vary widely - from 80 percent of the population in some government policies to 18 percent in reports by minority rights advocates (Nyati-Saleshando 2011; NCE 1977).

Indigenous to Botswana are also many non-Setswana-speaking ethnic groups who live throughout the country but are concentrated in the west and north (Pansiri 2012; NyatiRamahobo 2006). The largest of these groups include the Basarwa, Bakgalagadi, Bakalanga, Wayeyi, Ovaherero, Basubiya, and Ovambukushu. With the exception of the Basarwa (known internationally as the Khoisan), each of these groups speaks a single language that is mutually unintelligible with Setswana but in the same Bantu language family. The colonial-era census of 1946 was the last to ask residents to indicate their ethnic background (Nyati-Ramahobo 2006). The only nationally representative data that includes self-reported measures of ethnic group in Botswana is the Afrobarometer. In the three years in which data on ethnicity is available (2005, 
2008, and 2012), slightly more than half of respondents identify as Tswana and just under half identify as one of 21 other ethnic groups.

Ethnic minorities have been geographically, politically, and economically marginalized. Hierarchical in nature, pre-colonial Tswana kingdoms placed ethnic minorities in positions of serfdom (Gulbrandsen 2012). Post-colonial development in agriculture, the central livelihood for Batswana, was concentrated in Tswana-dominated regions (Leith 2005). Further, only Tswana groups have Constitutionally-granted political representation in the House of Chiefs (Republic of Botswana 1966). These marginalizations are explored in more detail in our analysis. While a pure majority/minority dichotomy is a false one, the eight Tswana groups constitute what are usually described as the 'majority', while the unacknowledged but self-identifying non-Tswana ethnic groups make up the 'minority.'

Peace and stability are not fixed characteristics of Botswana and, in fact, appear to be improbable outcomes. In what ways did the state act through educational institutions and policies to disrupt potential conflict? We explore conceptual mechanisms below before turning to empirical evidence.

\section{Disrupting Resource-based and Identity-based Inequalities}

Education can mobilize ethnic diversity toward conflict when, in its structures and/or content, it creates or exacerbates inequalities. Such is particularly true when such inequalities exist between groups. Inequalities that exist among individuals, "vertical inequalities," are not associated with intergroup conflict (Fearon and Laitin 2003; Collier and Hoeffler 2004). However, inequalities between groups, "horizontal inequalities," are associated with intergroup conflict (Østby 2008; Cederman, Weidmann, and Gleditsch 2011). Ethnic inequalities in 
particular predict conflict; perceived inequalities, even in the absence of verifiable evidence, can be just as pernicious (Brown and Langer 2010).

Evidence for the ways in which education can lead to conflict may be summarized as falling into two main categories: resource-based inequalities and identity-based inequalities. Countries that experience conflict often exhibit significant inequalities in the allocation of educational resources among ethnic groups. In 2001 in Nepal, for example, the literacy rate among the ruling Brahmins was 70 percent compared with only 10 percent among the lower/excluded castes (Novelli and Smith 2011). Similarly in pre-genocide Rwanda, promotion past primary school was tied to ethnic group, with secondary school entrance allocated according to ethnic quotas such that Tutsi were required to have higher scores than Hutu (King 2014, 89). Identity-based inequalities create "us vs. them" oppositions and stigmatization (see King 2014, 19). These inequalities can manifest in curriculum, through symbols, values, and particularly through historical narratives. For example, a 1994 Bosnian civics textbook for junior secondary school condemned the "[h]orrible crimes committed against the non-Serb population of Bosnia and Herzegovina by Serb-Montenegrin aggressors" (Heyneman 2000). As Heyneman argues, whether or not these events occurred needs to be kept separate from the distance such a narrative can create between students $(2000,182)$ and the contributions such narratives can make to identity-based inequalities linked to conflict. In particular, individuals who experience identity-based inequalities, such as through negative characterization or marginalization in curricula, often have weak identification with their nation-states (Osler and Vincent 2002, 114127; Banks 2008, 133), which could lead to less stake in the protection and promotion of peace and stability. 
If resource-based and identity-based inequalities can link education to conflict, how might redistribution of resources and recognition of identities disrupt inequalities and link education to peace? Fraser (2010) draws out the salience of distribution and recognition in her work focused on gender, with important implications for ethnicity. In order to avoid inequalities and to foster what she calls "parity of participation," resources must be distributed so as to mitigate disparities that prevent full participation. In most cases, this requires the redistribution of resources in order to rectify existing inequalities. The massive expansion of access to education in post-genocide Rwanda, for example, represented a redistribution aimed at redressing past inequalities. Equitable distribution of resources could also be preemptive, intended to prevent conflict.

Marshall (2009 [1950]) argued that the distribution of resources is in fact a critical dimension of citizenship. Social citizenship is the promise of access to social services, including education, that allow for full participation in society. Yet as Banks (2008) noted, following Lipset, Marshall's typology is based on an "assumption of equality." Banks argued for expansion of the conception to include cultural citizenship that addresses exclusion of ethnic and linguistic minorities $(2008,130)$. The implication is that identity-based inequalities can be countered through recognition. Recognition involves all people having equal respect and status and the ability to participate fully in society (Gutmann 2003).

Education can foster recognition through curriculum, such as through multicultural education, which aims to ensure, for example, that the contributions of diverse groups are integrated into the history curriculum (Freedman et al. 2008; Paulson 2015) and embodies "respect for individuals and their equal rights as citizens" (Gutmann 2004, 80). It is not only the 
intent of curricular recognition but its outcomes that are critical: recognition is only realized when diverse children have equal chance at school success (Banks and McGee Banks 2001). Political theorists continue to debate the extent to which this recognition strengthens societies by enabling full participation by all against the potential costs vis-à-vis "weakening citizens' ability to communicate, trust, and feel solidarity across group differences" (Kymlicka and Norman 2000, 10). Education is frequently the frontline in managing this tension, called upon to counter "us vs. them" conceptualizations and to promote shared understandings and common goals. The mechanisms can be both curricular and relational. Curriculum that focuses on skills, beliefs, and attitudes that encourage openness to multiple perspectives and empathy toward other groups can build relationships and experiences that reflect what Kymlicka and Norman called "a new transcendent identity" $(2000,14)$. In divided societies, Bar-Tal and Rosen (2009) emphasized the importance of reflective thinking, tolerance, empathy, human rights, and conflict resolution in reducing conflict among groups. Research in social psychology illuminates the ways in which unity in diversity might occur through exposure to this type of education. When individuals come to see themselves as mutually interdependent, they can begin to "feel a sense of "we-ness"' (Turner et al. 1987, 34). The resulting common group identity can mitigate the liabilities associated with heterogeneity (Gaertner and Dovidio 2000). The persistent question is the extent to which this type of common group identity can enable recognition and disrupt identity-based inequalities.

Through the lens of resource-based and identity-based inequalities, and their corollaries of redistribution and recognition, we examine the ways in which Botswana has negotiated national unity and ethnic diversity in education and how these experiences have informed its pathway to peace. 


\section{Methods}

We used process tracing to draw inferences about past events and to develop an understanding of processes and the causes of particular outcomes (Bennett 2010; Collier 2011). We sought both to explain and to build theory around processes of negotiating national unity through education in the face of ethnic diversity and the threat of conflict. Our analysis involved three types of evidence: documents, interviews, and data from the nationally-representative Afrobarometer survey.

In order to understand the negotiation of national unity and ethnic diversity in Botswana, we selected and analyzed key documents. Six documents comprise Botswana's postindependence policy frameworks in education and in issues related to ethnic diversity, and we conducted a close textual analysis of all of them: (1) the 1977 report of the National Commission on Education, called Education for Kagisano, which was the first post-independence policy, many years in development; (2) the 1994 Revised National Policy on Education (RNPE); (3) the report of the National Commission on Education (1993) on which the RNPE was based; (4) the vision statement that guides all planning and policy in the country, Vision 2016; (5) the 2000 report of a Government commission investigating the presence of discrimination in the Constitution, the Presidential Commission of Inquiry into Sections 77, 78, and 79 of the Constitution of Botswana; and (6) the 2001 National Policy on Culture. We also decided to analyze the most recent national planning document, National Development Plan 10 (2009-2016) and its mid-term review for insight into more recent thinking, given the dearth of new education policies. 
School syllabi were a second set of documents that we analyzed. We read and coded each objective in all of the post-independence Junior Secondary School (JSS) Social Studies Syllabi $(1994,1996$, and 2010) to identify portions of the curriculum related to our research questions. These objectives represent "authorized knowledge" as approved by the Ministry of Education, and they guide the organization and content of textbooks and national exams. Social studies is charged with teaching students "the national principles and the ideals upon which the nation of Botswana is built" (Republic of Botswana 2010, i). JSS marks the final three years of Botswana's free ten-year basic education program and the end-point of formal education for most Batswana. Educational research in other historical periods and our own contemporary research reveal that teachers exhibit high fidelity to the written curriculum (Fuller and Snyder 1991), such that Tafa labeled them 'technicians' $(2004,757)$.

Interviews with key informants complemented our analysis of policy documents and syllabi. We conducted these in-depth interviews ( $\mathrm{n}=13$ ) between July 2013 and August 2014. In process tracing, interviews are designed to corroborate and elaborate on documentary historical evidence, so we chose interview participants who held knowledge that could not be gleaned from documentary sources alone and who occupied a range of positions, both internal and external to policy development and implementation processes. We identified key actors from our document analysis, guidance from colleagues at the University of Botswana, and through a snowball approach. We conducted interviews until we reached saturation, in other words we began to hear similar perspectives on the issues under study; we further tested the emergence of themes in ongoing analysis and, when we ceased to find new ideas and explanations, we developed confidence that our data represented the existing range of patterns to sufficiently answer the research question (Guest, Bunce, and Johnson 2006). Our final interview sample included 
Ministry of Education staff (political appointees and civil servants), leaders of human rights and language advocacy groups, academics, a textbook writer, and a member of the Vision 2016 Commission (see Table 1).

We asked interview participants to describe their views on, for example, policy-making processes; how and to what extent policies were implemented; the principles that guide national unity; and the relationships between inequalities and ethnic diversity. We developed individualized interview guides for each interview participant based on position and experiences, for example, asking the textbook writer about how the syllabi guided decisions on textbook content. There were also common questions across interview guides including but not limited to: What do children learn about national unity in school?; Tell me about Education for Kagisano and the RNPE: what national goals did they express?; What do you think, is there a shift away from monoculturalism in schools now? Tell me what you see taking place. After each interview, we listened to the recording and wrote in-depth notes on all of the content, including some verbatim quotes, and wrote analytic memos on emerging themes.

To trace the changing discourse between 1977 and 2014 around national unity, we identified excerpts from the documents that a) defined or operationalized national principles or goals, b) discussed ethnic, linguistic, or regional diversity, c) contextualized the reasoning behind or process of creating the policy, d) discussed elements that comprise national identity, or e) described how the education system would help build national unity. Through initial analyses, we identified code families, related to access, equity, quality, participation, national principles, and identity. We coded the document excerpts at the line level, identifying patterns within and across data sources. We analyzed patterns in the relative importance of different components of national identity over time. We analyzed the interview notes using the same coding structure, but 
with a specific focus on explanations for the changing patterns observed in the document analysis.

We also analyzed data from the nationally-representative Afrobarometer survey, a large public opinion dataset. Data is collected using national probability samples for all citizens of voting age. The sample is a clustered, stratified, multi-stage, area probability sample, which seeks to reduce the likelihood that ethnic groups are excluded from the sample. The sample size of 1200 in Botswana allows inferences to the national adult population with a margin of error of +/- 2.8 percent with a confidence level of 95 percent. In each year of the survey, there were 1200 respondents, for a total of 6000 respondents over five administrations of the survey $\left(1999^{1}, 2003\right.$, 2005,2008 , and 2012); we used data from all five years. The data is self-weighting, aside from 2008 and 2012, which we weighted appropriately using the weights provided by Afrobarometer. We created a variable for ethnicity to group respondents who (a) identify themselves as belonging to one of the eight "major" tribes in Botswana, who are recognized in the Constitution and include Setswana speakers, or (b) identify themselves as belonging to another ethnic group. ${ }^{2}$ The former we conceptualize as 'majority' ethnic groups, the latter as 'minority' ethnic groups. ${ }^{3}$

[Table 1 about here]

\section{Building National Unity within Ethnic Diversity: Botswana's Approach}

Below, we trace the evolving nature of Botswana's approach to the dilemma of constructing national unity in the presence of ethnic diversity through four "moments." The first moment analyzes the development of Education for Kagisano (1977), Botswana's first postindependence education policy document, which embraced the majority indigenous language, Setswana, and promoted elements of Tswana culture as the basis of the national identity of all 
citizens, including members of ethnic minority groups. The second moment explores the development of the Revised National Policy on Education (1994). The RNPE shifted away from the promotion of Tswana culture, but rejected the recommendation of its precursor National Commission on Education (1993) to introduce minority language instruction in schools and instead emphasized the need for all citizens to learn Setswana. The third moment analyzes Vision 2016, drafted in 1997 to articulate national goals for the $50^{\text {th }}$ anniversary of independence. Vision 2016 departed from the conception of Tswana-based national identity, calling for recognition of ethnic diversity and minority language instruction in schools. The final moment examines the Balopi Commission, which investigated discrimination in the Botswana Constitution, and its aftermath, a time period of direct challenge to Government policies, the formation of language advocacy groups, and continued agitation for the teaching of minority languages in schools. Figure 1 illustrates these moments.

[Figure 1 about here]

\section{Moment 1: The Building of National Unity}

For the first decade of independence, there was no new education policy in Botswana and colonial British policies remained in use (Interview \#8). In 1975, the National Commission on Education (NCE) was established to review the education system in Botswana. The Commission found that "education generally has failed to satisfy the hopes of Batswana" (NCE 1977, 1). Its report formed the basis of Education for Kagisano, the first post-independence education policy document, published in 1977, which aimed to create an education system that would fulfill those hopes. 
A current leader in the Ministry of Education described this policy as "education for nation-building” (Interview \#10). Our analysis reveals two main guiding purposes for education in Botswana: first, bringing all Batswana into the economy; and second, the building of national unity through kagisano, or social harmony. The economic and social aspects of nation-building both have implications for unity and ethnic diversity. Education for Kagisano envisions "national unity" as a) equitable access to educational resources across regions and socioeconomic groups, which could be characterized as redistribution, combatting resource-based inequalities; and b) a homogeneous national culture based on the national principles and the language and culture of the majority Tswana ethnic group, a lack of recognition that leaves open possibilities for identity-based inequalities.

The first purpose of education was for economic development. Economic development could be best fostered, the Commission argued, through the equitable distribution of educational opportunities - to rectify the "[h]itherto... stratified and hierarchical" education system (NCE 1977, 212). Instead of focusing on secondary and tertiary education, which it labeled "socially divisive," it advocated the expansion of primary education to avoid "a society which is polarised between rich and poor, urban and rural, well-educated and semi-literate, a privileged minority and an underprivileged majority" (NCE 1977, 210).

The second purpose of education in Education for Kagisano was related to social harmony. This purpose was not unconnected to the equitable provision of educational opportunities and, again, centered on redistribution. The Commission wrote that "[i]t will not be possible to speak of the achievement of unity and social justice in Botswana while many children are deprived of access to school" (NCE 1977, 58). Equity between ethnic and language groups arose only twice in this document (NCE 1977, 12, 32). The Commission warned against bias in 
national exams that might exclude children in rural areas, from poor families, and from "certain language groups" and cautioned that "[i]n any consideration of language policy, the rights and needs of the linguistic minority groups must be considered carefully, together with educational and national unity factors" (NCE 1977, 32). There were no specific policy recommendations for addressing these needs.

The Commission defined not only equitable access to individual development as central to social harmony, but also certain content of education necessary to foster this harmony. Education for Kagisano described the four national principles that schools should promote: democracy, development, self-reliance, and unity (NCE 1977, 24). These principles were seen as central to a liberal-democratic nation-building agenda (see Carnoy, Chisholm, and Chilisa 2012, 17). They were not specific to one ethnic or language group, were put forth in the context of equity.

Our analysis, however, reveals an explicit sub-text of nation-building premised on monolingualism and monoculturalism (see also, Nyati-Ramahobo 2006; Tabulawa 2009; 2011, and for analysis of these issues outside of education, see Werbner, 2002). Tswana culture and the Setswana language were privileged: "Tswana language and culture must be part of the intellectual development of every child in Botswana” (NCE 1977, 110). The Commission noted that "[i]t is of paramount importance to the national consciousness that every citizen of the country should be fully proficient in Setswana" (NCE 1993, 111) and that "Setswana is a vital medium of communication in the country and is the vehicle through which the national culture is largely expressed" (NCE 1977, 177).

The policy further defined national culture as Tswana culture and established that all students complete "Tswana language and culture" as one of six curricular areas required 
throughout primary and secondary school, "as a source of both the ability to communicate in the national language and a sense of national unity" (NCE 1977, 108, 110, 113). The adopted language policy named Setswana as the language of instruction for the first four years of school and English thereafter.

Education for Kagisano was the educational manifestation of what Werbner called the “One-Nation Consensus." This idea, established at independence, held that building one state required building one nation. It was "assimilationist, favouring homogeneity, fostered through one official and one recognised language, respectively English and Tswana" (Werbner 2002, 676). While this consensus was broad, it was by no means universal.

The need to build a strong, unified state is importantly contextualized in the regional realities of the time. The major priority, said a Ministry of Education staff member, was to be different from other countries that were engulfed in conflict (Interview \#8). The Commission wrote that "Botswana's education system has an important responsibility to express clearly the country's national principles and the spirit of a free, non-racial society at a time when neighboring countries are subject to internal turmoil and racial strife" (NCE 1977, 18).

The decision to emphasize economic development and social harmony through the synthesis of the four principles of democracy, development, self-reliance, and unity with a Tswana-based national identity was presented as necessary, the only pathway away from divisiveness within the state. The resulting "one nation" vision in education - as Gulbrandsen (2012) argues existed in society broadly - was intended as a method of avoiding conflict, even if that conflict was not outwardly manifest at the time. The cost was that the adopted model of unity did not include recognition of ethnic diversity and left open possibilities of identity-based inequalities. 
Moment 2: The Salience of Ethnicity and Language

In April 1992, the second National Commission on Education was mandated to review "the entire education system with a view to developing a system that would see the country into the twenty-first century" (NCE 1993, i). With continued economic growth and the ability to attract both foreign aid and foreign investment, expansion of education had been rapid in the intervening time: by 1985 , there were 558 primary schools, more than double the number at independence, and 68 secondary schools, up from nine. Education received the largest proportion of the recurrent budget, 22 percent (Republic of Botswana 1994, 12).

In 1994, the findings and recommendations of the NCE were published as the Revised National Policy on Education (RNPE). Despite being authored in 1994, interview participants noted that "[t]he RNPE is the main document guiding education policy in the country" at present (Interview \#4, also \#8,\#12). The main focus of the RNPE was economic development, with less attention paid to the social dimensions of education and nation-building. The policy noted that "[t]he education and training strategy as enunciated in the Commission's report will aim at ensuring that the people of Botswana, as a major national resource, will have invested in them an education necessary for national development" (Republic of Botswana 1994, Section 3.1). Unlike in Education for Kagisano, where 'national development' referred to both social and economic development, the RNPE stressed the latter. At the same time, the RNPE was more attentive to ethnic dimensions of equity and defined a specific language policy. Changes between Social Studies syllabi that came immediately before and after the RNPE also signified a shift in thinking about the recognition of non-Tswana ethnic groups. 
The RNPE emphasized redistribution: expanding access to the most marginalized children and young people who had to date been left out of mass educational expansion. Tabulawa $(2009,90-91)$ argued that this shift represented Botswana's "response to globalization" in that it aimed to prepare students to work in the post-Fordist global economy, citing the 1993 report of the National Commission on Education, which stated that "[t]he education system was extolled to 'offer individuals a lifelong opportunity to develop themselves and to make their country competitive internationally' (Republic of Botswana 1993, 4).”

At the same time, the RNPE newly identified ethnicity as one dimension on which students had been disadvantaged. Areas cited for lower enrollment rates -65 percent compared to 95 percent - and shortages of trained teachers -42 percent compared to 5 percent - were regions highly populated with non-Tswana ethnic groups and non-Setswana speakers. The distribution of educational resources for national development reflected horizontal inequalities, on the basis of ethnicity and language. Though these inequalities were explicitly reflected in the RNPE, related political conflict was only beginning to surface, and there were no instances of violence.

The RNPE also addressed recognition, citing the need to "improve the response of schools to the needs of different ethnic groups in the society" and "sensitizing teachers to cultural differences" (Republic of Botswana 1994, Section 3.2.e). Central to responding to the needs of ethnic minority students was mother-tongue instruction. The Commission acknowledged "the importance of Setswana as a national language and a unifying force" but concluded that "the present language policy denies the child mastery of the main language tool [local language] needed for better achievement in primary school and in further education and in working life" (NCE 1993, 113). It recommended that children be taught initially "the language 
dominant in the area where the school is located," with English and Setswana gradually introduced thereafter (Republic of Botswana 1994, Recommendation 12). While this recommendation created an opportunity for recognition, Parliament did not accept the recommendation, noting a lack of resources and being "contrary to national language policy" (Republic of Botswana 1994, 84-85). This decision to continue promoting monolingual national unity contributed to lack of recognition and the beginnings of organized dissent among minority groups (Nyati-Ramahobo 2006, 208-209).

One area of significant change was that, unlike Education for Kagisano, the RNPE never mentioned instruction in "Tswana culture." We see further evidence of a shift from Tswanadominated curricular content in syllabi. In 1994, the first overall aim was to "show knowledge and understanding of Tswana culture, language, literature, arts, crafts and traditions" (Republic of Botswana 1994, 1). By 1996, this aim had disappeared completely and most of the 15 aims related to employment readiness. The framing of cultural knowledge in the relevant aim in 1996 was oriented away from monoculturalism and toward recognition of many cultures, expecting that learners will have: "acquired knowledge and understanding of society, appreciation of their culture including languages, traditions, songs, ceremonies, customs, social norms and a sense of citizenship" (Republic of Botswana 1996, ii).

This shift away from Tswana culture in the 1994 RNPE and resulting syllabus reflected local political and social realities. The RNPE was released eight months before a national election, as much a political manifesto and policy of appeasement - related to economic competiveness, and youth unemployment in particular - for the incumbent party as it was an education policy (Tabulawa 2011). Further, Zimbabwe and Namibia were relatively peaceful at this time, and South Africa was embedding cultural and linguistic rights in its new Constitution. 
A Ministry of Education staff member reflected that the era of the RNPE was one with less fear of armed and violent conflict than the era of Education for Kagisano (Interview \#8), and yet this era surfaced identity-based inequalities and heralded a transition from unchallenged assimilatory policies toward more nuanced conceptions of unity.

\section{Moment 3: Unity in Diversity}

The process of developing Vision 2016, initiated in the mid-1990s, continued the spirit of the RNPE. It was, as a member of the Vision 2016 Task Group said, "like a referendum with one question" (Interview \#7), that question being "What kind of society would we like Botswana to be by the year 2016 [the fiftieth anniversary of independence]?” (Presidential Task Group (PTG), 1997, 1). Based on extensive consultations, "[t]he national Vision was conceptualised to be a product reflecting broad consensus of the Botswana population," the Task Group wrote (1997, 79). "It belonged to the nation," said a member of the Vision 2016 Task Group (Interview \#7).

From the Vision 2016 consultations, education was "clearly the number one pillar" (Interview \#7), and the First Pillar of the finalized Vision 2016 was “An Educated, Informed Nation" (PTG, 1997, 5). The implementation section of the Vision noted that "[t]he new policy on education [the RNPE] is an important step in the realization of the Vision, and it will need to be vigorously implemented and developed" (PTG, 1997, 28). Echoing the RNPE, Vision 2016 contained a clear emphasis on the role of education for economic development. The social purposes of education were also clear, particularly related to recognition of ethnicity.

Importantly, Botswana had rectified some of the horizontal inequalities identified in the previous Moment. For example, in 1975-1976, 69 percent of the variance in mathematics achievement was due to school factors, particularly resource inputs; by 1989, only 12 percent of 
the variance was between schools (Marope 1996). Yet within school variance remained high. While framed in policy dialogue as a vertical inequality rather than a horizontal one, some students were not doing as well as others. Peaceful pressure from ethnic minority groups began to grow at this time, and while Vision 2016 lacked the implementation powers of a policy, it catalyzed an important shift to focus on issues of recognition in education.

Vision 2016 stated that "Botswana contains a diversity of tribes with different languages that are not equally recognised, and there are signs of disunity and separateness." Central to the purpose of the Vision was "to meet the challenge of building a united nation that harnesses this diversity" (PTG, 1997, 26). The conceptualization of unity in Vision 2016 diverged from previous Moments in three key respects: first related to equity and a shift from redistribution to redistribution plus recognition; second related to the elements of commonality; and third related to understanding of the cultural composition of the country. The points of commonality in Vision 2016 consisted not of a homogeneous language and culture but of "common goals," "a common heritage," and "a common destiny." In direct contrast to Education for Kagisano's vision of national unity built around Setswana language and Tswana culture, Vision 2016 highlighted the continuing presence of "a diverse mix of cultures, languages, traditions, and peoples." The terms "ethnic integration," "full partnership," and "nation in harmony" connoted a unity that arose from a shared tolerance for ethnic diversity rather than assimilation to a single, dominant ethnic culture.

Vision 2016's final education goal also reflected this shift by attending to linguistic diversity. It stated that "Botswana's wealth of different languages and cultural traditions will be recognised, supported and strengthened within the education system" (PTG, 1997, 5) such that "all of the nation's languages must be taught to a high standard at primary, secondary and 
tertiary level" (PTG, 1997, 26). Unlike the education goals that pertained to economic development, however, this goal for addressing linguistic diversity in schools was not implemented, showing continued lack of movement on this issue.

Vision 2016 reflected the rising public salience of marginalization of ethnic minorities in Botswana. It was a time of advocacy, particularly in the area of language rights, and of formation of language and cultural groups among the Kalanga (1986), Wayeyi (1995), and Batswapong (1998) (Nyati-Ramahobo 2006; Nyati-Saleshando 2011, 573), as well as of Tswana opposition to these groups, particularly by the nationalist group Pitso Ya Batswana (Gulbrandsen 2012). This dissent was, in all instances, peaceful. The political response was mixed. President Masire publically warned of the dangers of "letting the tiger loose" (Werbner 2002), meaning ethnic tensions. Subsequently, President Mogae advocated for the activities of cultural organizations, but on the condition that they promote national unity rather than divisiveness.

In this context, Vision 2016 seemed to be the realization of a new understanding of national unity, one based not on Tswana culture and language but on ethnic and linguistic diversity (Interviews $\# 1,2,4,5,6,7,8,11,13$ ). Despite lacking implementation power, a social studies textbook author described Vision 2016 as a major shift for the everyday life of citizens of Botswana: it ushered in an era in which "[b]eing different [meaning non-Tswana] does not mean being inferior..." (Interview \#11). Echoed in the 2005 Afrobarometer survey, members of both majority ethnic groups and minority ethnic groups perceived that their ethnic groups were never treated unfairly by Government, 71 and 61 percent respectively.

Concrete shifts prompted by Vision 2016 were nevertheless limited because it lacked the implementation powers of policy documents. A Ministry of Education leader stated that Vision 2016 "allows you to dream, but now when you come to put in an actual plan, you have to cut 
your dream into step by step and what is realistically possible" (Interview \#4). On the recommendations vis-à-vis languages in schools, he noted, "it will be difficult to attain them." A member of a language rights NGO noted "total resistance" for coming up with an implementation-ready language policy (Interview \#5). A professor at the University of Botswana described what he saw as "subtle pushback," in blaming the failure to implement the language recommendations of Vision 2016 on the lack of resources rather than recognizing the reality he saw: the lack of political will (Interview \#13). Another professor explained his view that even in the aftermath of Vision 2016, "[t]eachers are trained as if we are a monocultural society, a one language society" (Interview \#6).

A member of the Vision 2016 Task Group described Vision 2016 as “just a song.” He said, "apart from the Bible, this is the most quoted book in the country. But I don't think the behavior reflects the book.... I don't see it having shaped behavior of leaders." Despite the conversations that Vision 2016 catalyzed, if he were to write a book on the process, he said, it would be called "Vision 2016: A Vision Betrayed" (Interview \#7).

\section{Moment 4: A Vision "Betrayed”}

Education for Kagisano, the RNPE, and Vision 2016 agreed on the importance of establishing a strong sense of national unity to bring all citizens of Botswana together and on the essential role of education in so doing. The 1993 NCE and Vision 2016 identified key educational mechanisms for meeting the needs of ethnic minorities, specifically using minority languages in schools. Vision 2016 also gave cultural and language advocacy groups an opening for recognition, to see their views reflected in the national dialogue. However, with the rejection of the 1993 NCE recommendation and increasing consensus that the tenets of Vision 2016 were 
rhetoric alone, the era after Vision 2016 was a time of direct challenge to the Constitution and Government policies, specifically those in education that fell short of meeting redistribution and recognition needs of ethnic minorities. These formal challenges to resource-based and identitybased inequalities were unprecedented in post-independence Botswana and represented a shift in the ways in which issues of national unity and ethnic diversity were addressed. What remained consistent was the lack of violence.

Importantly, this time was also characterized by strong feelings of unity. In 2003, only 28 percent of respondents to the Afrobarometer survey described their ethnic identity as the group they belong to first and foremost, whereas 95 percent had described themselves that way in 1999. ${ }^{4}$ Further, 42 percent of respondents in 2003 said either that they did not differentiate themselves in a way other than being a citizen of Botswana or that they had only a national identity; in 1999, less than 1 percent had said they did not differentiate and a little over 2 percent said only Motswana, equivalent to national identity. In this way, and critical to Botswana's unique pathway toward peace, dissent occurred within a context of unity.

Yet with burgeoning advocacy for equal recognition and direct political challenge by a Wayeyi group to the Constitutional arrangement whereby only Tswana groups were represented in the House of Chiefs, President Mogae established the Balopi Commission to investigate discrimination in the Constitution. An observer of the process noted that "the Commission went around the country and 'wow,' 'wow,' wow.' People spoke and you could hear that people had just been boiling. They see the discrimination but they just didn't know what to do with it.... Even some of the Setswana people were saying, 'we can't live in a country where we still discriminate against other people, it's not right, it's not right"' (Interview \#1). One primary piece 
of evidence in documenting discrimination was educational policy that did not recognize minority languages (Nyamnjoh 2002, 760).

The Commission found that citizens still self-identified along ethnic lines and believed that preference for Tswana citizens was ingrained in the Constitution itself. The report concluded that "if the Constitution was not amended, the long-term stability of this country, and in particular, the sustainability of its unity, could not be guaranteed" (Republic of Botswana 2000, 9). The momentum of the Balopi Commission catalyzed minority groups and enabled coalitionbuilding around both redistribution of educational resources and recognition in education, through language and content. The Commission's report also presented a clear path for mitigating resource-based and, in particular, identity-based inequalities.

The Government's response, however, did not adopt this path and fell short of these groups' hopes. A revised White paper, accepted in mid-2002, promised the discriminatory sections of the Constitution would be amended at an unspecified date, but maintained the privileged position of the eight Tswana chiefs (Nyati-Ramahobo, 2006a; Werbner, 2002). In 2001, Parliament passed the National Policy on Culture. Like Vision 2016, this new policy affirmed ethnic diversity as central to national identity and named the formal education system as the key institution for "enculturation" yet did not act on inclusive curricular content or instruction in minority languages (Republic of Botswana 2001). Instead, research on and development of minority languages and cultures was left to private organizations (NyatiRamahobo 2006, Interviews \#1, 5).

More than ten years after the Balopi Commission and the National Policy on Culture, only small changes have been made to the educational approach to national unity based on Tswana culture and language. The phrase "unity in diversity" was included in the 2010 Social 
Studies syllabus, as one of the aims: "learners should have developed tolerance towards different cultures, pride in own culture and unity in diversity" (Republic of Botswana 2010). Yet there is wide agreement that this shift is superficial (Interviews \#1, 2, 4, 5, 6, 7, 12). NDP10 does not acknowledge ethnicity or language to be the basis of disadvantage or vulnerability within the education system (Republic of Botswana 2009, 105). As Fraser (2000) warned, as claims for recognition emerge, pressure for redistribution can fade. Further, while the National Policy on Culture enables cultural festivals celebrating both majority and minority groups, they are perceived as "tokenism," recognition of diversity that is confined to a few days and for which there continues to be little space in schools (Interviews \#1, 5, 6). A University of Botswana professor reflected, "You are only brought in to come and dance, to dress in your own culture, to appear primitive," he said. Real change would only occur, he stated, if education "promoted your language" and "the school system promoted your culture" (Interview \#6).

Vis-à-vis language of instruction in schools, "a decision has not been taken on these issues," said a Ministry of Education leader. The "resource requirements" are not in place, she said, and the Ministry of Education has prioritized access (Interview \#10). While Parliament has continued to debate ethnic and linguistic equity and language advocacy groups work privately to develop educational materials in minority languages, the education system maintains English and Setswana as the only languages of instruction.

This period of agitation for recognition exemplifies the interethnic tensions that do exist in Botswana. These tensions could have been grounds for violent conflict. In Botswana, however, they were not. Amidst the dissent remained an underlying sense of unity, carefully inculcated, as we have seen, since independence. By 2012, Afrobarometer data reveal that 64 percent of Tswana and 68 percent of minority ethnic group members described feeling equally 
Motswana and their ethnic group, with only 6 percent of each feeling only ethnic. Further, 77 percent of both Tswana and minority ethnic groups strongly agreed with the statement, "It makes you proud to be called a Motswana."

\section{Conclusion}

In drafting Vision 2016, the question asked of citizens of Botswana was, "What kind of society would we like Botswana to be by the year 2016?” Two widespread responses to this question were stable and free from discrimination. The most peaceful society in sub-Saharan Africa, Botswana has, to date, achieved the former. Has this stability, however, come at the expense of freedom from discrimination? And, if so, are there consequences for ongoing stability?

As we demonstrate, post-independence Botswana chose to construct national unity through schools, with the intention of disrupting patterns of violent conflict that existed in neighboring countries. This unity was initially premised on the dominant Tswana culture and Setswana language. At the same time, attention to redistribution was high, and the government massively and quickly expanded access to education. This redistribution fostered perceptions that members of all ethnic groups could share in national prosperity. Civic principles of social harmony further inculcated among citizens of Botswana a sense of pride in being Motswana. Despite ethnic differences, with this overarching sense of common belonging and shared resources, there was less chance of inequalities being perceived as connected to a particular group - at least in perception, they remained vertical inequalities rather than horizontal ones.

The decision to build national unity around Tswana culture and the Setswana language nevertheless also had costs. The aftermath of Vision 2016 and the Balopi Commission 
demonstrated important concerns about discrimination in Botswana. This more recent period highlighted lack of recognition of ethnic minorities, particularly as manifest in school curriculum and language of instruction policies. These identity-based inequalities are horizontal inequalities, and they are increasingly perceived as such in Botswana. Are the very policies that were aimed at promoting national unity now a threat to the ongoing stability of Botswana?

Experiences of identity-based inequalities are often associated with weak identification with the nation-state. Yet minority groups in Botswana continue to express identification with the nation-state; they are overwhelmingly proud to be Motswana. The question remains as to whether such a commitment to the nation-state can create conditions for recognition and the disruption of existing identity-based inequalities to enable full participation in society by all. On this question, our process-tracing analysis of Botswana's experiences negotiating national unity and ethnic diversity has implications for other multiethnic nation-states and for the future of Botswana itself.

Our analysis points to three mechanisms by which Botswana may have cultivated national unity despite limited redress of identity-based inequalities, with important caveats on the need for further research. First, redistribution of educational resources has been high, palpably felt by most Motswana and perceived as a share in the wealth of the nation-state. Second, and related, high rates of access to education across ethnic groups mean that most Motswana have frequent contact with government institutions and the social citizenship they provide. Globally, communities often create alternative education in response to culturally and linguistically assimilationist practices. These separate structures often entrench conflict, such as in Northern Ireland, Sri Lanka, and Bosnia and Herzegovina (Bush and Saltarelli 2000; IIEP 2011). More 
research is needed to understand why minorities in Botswana have not created such structures and the implications for national unity and recognition.

Third, responses to identity-based inequalities in Botswana have been markedly different from other contexts, such as South Africa, Yugoslavia, Sri Lanka, and Nepal, where tensions over cultural content of curriculum and language of instruction have been cause for violent conflict and sometimes catalysts of civil war. Our analysis points to the possible impact of swift and tangible redistribution of resources and attention - albeit incomplete - to issues of recognition as mechanisms to mitigate marginalization. Importantly, these actions appear connected to the transformation of inequalities, or at minimum the perceptions of inequalities, from horizontal ones based on ethnicity to vertical ones. Our analysis has further uncovered markedly different responses to existing and continued identity-based inequalities in the form of political pressure and ongoing dialogue rather than violent conflict. Some scholars credit the kgotla, communal decision-making bodies in Botswana where conflict resolution occurs through discussion (Gulbrandsen 2012); while kgotla are originally Tswana institutions, ethnic minorities have participated in them, in varying capacities, since pre-colonial times. Further research is needed into more contemporary participation in kgotla and other bases for observed peaceful methods of dissent, including related to the possible role of education, in its content and pedagogy. Moreover, further research is needed to better understand the perceptions of both historical and contemporary identity-based inequalities and their relationships to current feelings of unity and/or resistance, held by majority and minority ethnic group members.

Unlike in neighboring countries whose trajectories Botswana worked so explicitly to avoid, violent conflict has not erupted. National unity, premised on monocultural and monolingual identity but accompanied by redistribution of resources, may have played an 
important role in cultivating this stability, including in promoting peaceful dissent. The process of developing national unity may have broken down barriers to cooperation (Nyati-Saleshando 2011), specifically enabling the vast majority of citizens to feel Motswana and to be able to talk to each other through a shared language. Overwhelmingly, citizens do not want to give up being Motswana or speaking Setswana. Many do, however, wish for greater recognition of their ethnicity and, as we have demonstrated, serious tensions exist as a result.

Ongoing lack of recognition and persistent identity-based inequalities may now pose a threat to continued stability. Political and educational theorists are increasingly in agreement that unity and recognition are not mutually exclusive and that, in fact, in multiethnic societies, unity may not be fully possible without recognition (Kymlicka and Norman 2000; Banks 2008). Yet the balance between unity and recognition is importantly embedded in context. The threat of conflict in post-independence Botswana lent gravity to unity, even for those whom that unity could harm through lack of recognition. The current context, however, has shifted, and the threats are different. As our analysis has shown, there are high levels of unity in Botswana. In this context, ethnic diversity is no longer the critical threat to be managed by the state; the contemporary threat is limited recognition of ethnicity and language, perpetuating identity-based inequalities and lack of full participation. Peace is not a fixed characteristic, and the ultimate test will be the adaptability of the nation-state to address these current threats.

\section{Notes}

\footnotetext{
${ }^{1}$ In 1999, the historically non-Tswana districts of Ghanzi, North East, Kgalagadi, and North West/Ngamiland were not included in the sample.

2 The question was asked as follows: 2005 and 2008: "What is your tribe? You know, your ethnic or cultural group" and 2012: "Let us get back to talking about you. What is your ethnic community, cultural group or tribe?" Response was open and recorded exactly as stated by the respondent.
} 
${ }^{3}$ We examined results that included nine ethnic groups first as part of the majority group and then as part of the minority group (Mohurutshe, Mokhurutshe, Mmirwa, Mongologa, Motswapong, Motlharo, Motlhaping, Mokgothu, and Motalaote). These ethnic groups speak languages that are mutually intelligible with Setswana. We ultimately decided to include them in the minority group following Boikhutso and Jotia (2013); given the existence of language advocacy organizations for some of these groups (e.g., Lentswe la Batswapong); and based on our own field-based work in which members of these ethnic groups described stigma they faced in language use and experiences in school similar to those of other ethnic minority groups. The number of respondents in these nine additional ethnic groups combined was small (14.2\% of the sample in $2005,15 \%$ in 2008 , and $11.7 \%$ in 2012$)$, and the analyses show no substantial differences whether they are categorized as majority or minority.

${ }^{4}$ The question is phrased as follows: "We have spoken to many People in Botswana and they have all described themselves in different ways. Some people describe themselves in terms of their language, religion, race, and others describe themselves in economic terms, such as working class, middle class, or a farmer. Besides being a citizen of Botswana which specific group to do you feel you belong to first and foremost?" 
Table 1. Interview Participants ${ }^{5}$

\begin{tabular}{ll}
\hline Interview No. & Type of Organization \\
\hline 1 & Language Rights NGO \\
2 & Human Rights NGO \\
3 & Language Rights NGO \\
4 & Ministry of Education, Central Office \\
5 & Language Rights NGO \\
6 & University \\
7 & Vision 2016 Task Group \\
8 & Ministry of Education, Central Office \\
9 & Ministry of Education, District Education Office \\
10 & Ministry of Education, Central Office \\
11 & Textbook Author \\
12 & University \\
13 & University \\
\hline
\end{tabular}

\footnotetext{
${ }^{5}$ Many of the interview participants have more than one role and sphere of work. To preserve anonymity, we include here the most salient role from which they shared perspectives for this research.
} 


\section{References}

Acemoglu, Daron, and James A. Robinson. 2012. Why nations fail : the origins of power, prosperity and poverty. New York: Crown Publishers.

Alesina, Alberto, Arnaud Devleeschauwer, William Easterly, Sergio Kurlat, and Romain Wacziarg. 2003. Fractionalization. Journal of Economic Growth 8 (2):155-194.

Banks, J. A., and C. A. McGee Banks. 2001. Multicultural education: Issues and perspectives. 4th ed. New York: Wiley.

Banks, James A. 2008. Diversity, Group Identity, and Citizenship Education in a Global Age. Educational Researcher 37 (3):129-139.

Bar-Tal, Daniel, and Yigal Rosen. 2009. Peace Education in Societies Involved in Intractable Conflicts: Direct and Indirect Models. Review of Educational Research 79 (2):557-575.

Bennett, Andrew. 2010. Process tracing and causal inference. In Rethinking Social Inquiry, edited by H. Brady and D. Collier. Lanham, MD: Rowman and Littlefield.

Boikhutso, Keene, and Agreement Lathi Jotia. 2013. Language identity and multicultural diversity in Botswana. International Journal of Lifelong Education 32 (6):797-815.

Brown, Graham K., and Arnim Langer. 2010. Horizontal inequalities and conflict: a critical review and research agenda. Conflict, Security \& Development 10 (1):27-55.

Bush, Kenneth D., and Diana Saltarelli. 2000. The Two Faces of Education in Ethnic Conflict: Towards a Peacebuilding Education for Children. Florence: UNICEF, Innocenti Research Centre.

Carnoy, Martin, Linda Chisholm, and Bagele Chilisa. 2012. The Low Achievement Trap: Comparing Schooling in Botswana and South Africa. Cape Town: HRSC.

Cederman, Lars-Erik, Nils B. Weidmann, and Kristian Skrede Gleditsch. 2011. Horizontal Inequalities and Ethnonationalist Civil War: A Global Comparison. The American Political Science Review 105 (3):478-495.

Collier, David. 2011. Understanding process tracing. Political Science and Politics 44 (4):823830.

Collier, Paul. 2001. Implications of ethnic diversity. Washington, DC: World Bank.

Collier, Paul, and A. Hoeffler. 2004. Greed and grievance in civil war. Oxford Economic Papers 56 (4):563-595.

Davies, Lynn. 2011. Can Education Interrupt Fragility? Towards the Resilient and Adaptable State. In Educating Children in Conflict Zones: Research, Policy, and Practice for Systemic Change (A Tribute to Jackie Kirk), edited by K. Mundy and S. DrydenPeterson. New York: Teachers College Press.

Eifert, Benn, Edward Miguel, and Daniel N. Posner. 2010. Political Competition and Ethnic Identification in Africa. American Journal of Political Science 54 (2):494-510.

Fearon, James D. 2003. Ethnic and Cultural Diversity by Country. Journal of Economic Growth $8(2): 195-222$.

Fearon, James D., and David D. Laitin. 2003. Ethnicity, Insurgency, and Civil War. American Political Science Review 97 (01):75-90.

Fraser, Nancy. 2000. Rethinking recognition. New Left Review (3):107.

Repeated Author. 2010. Injustice at Intersecting Scales: On 'Social Exclusion' and the 'Global Poor.'. European Journal of Social Theory 13 (3):363-371. 
Freedman, Sarah Warshauer, Harvey M. Weinstein, Karen Murphy, and Timothy Longman. 2008. Teaching History after Identity-Based Conflicts: The Rwanda Experience. Comparative Education Review 52 (4):663-690.

Fuller, Bruce, and Conrad W. Snyder, Jr. 1991. Vocal Teachers, Silent Pupils? Life in Botswana Classrooms. Comparative Education Review 35 (2):274-294.

Gaertner, Samuel L., and John F. Dovidio. 2000. Reducing intergroup bias : the common ingroup identity model, Essays in social psychology,. Philadelphia, PA: Psychology Press.

Guest, Greg, Arwen Bunce, and Laura Johnson. 2006. How Many Interviews Are Enough? An Experiment with Data Saturation and Variability. Field Methods 18 (1):59-82.

Gulbrandsen, Ørnulf. 2012. The state and the social : state formation in Botswana and its precolonial and colonial genealogies. New York: Berghahn Books.

Gutmann, Amy. 2003. Identity in democracy. Princeton, N.J.: Princeton University Press.

Repeated Author. 2004. Unity and Diversity in Democratic Multicultural Education: Creative and Destructive Tensions. In Diversity and citizenship education : global perspectives, edited by J. A. Banks. San Francisco: Jossey-Bass.

Habyarimana, James, Macartan Humphreys, Daniel Posner, and Jeremy Weinstein. 2008. Is Ethnic Conflict Inevitable? Parting Ways Over Nationalism and Separatism. Foreign Affairs 87 (4):138-141.

Heyneman, Stephen P. 2000. From the Party/State to Multiethnic Democracy: Education and Social Cohesion in Europe and Central Asia. Educational Evaluation and Policy Analysis 22 (2):173-191.

IIEP. 2011. Understanding education's role in fragility: Synthesis of four situational analyses of education and fragility: Afghanistan, Bosnia and Herzegovina, Cambodia, Liberia. Pari: IIEP.

Institute for Economics and Peace. 2015. Global Peace Index: Measuring Peace, Its Causes and Its Economic Value. Sydney; New York; Mexico City: Institute for Economics and Peace.

King, Elisabeth. 2014. From classrooms to conflict in Rwanda. New York: Cambridge University Press.

Kymlicka, Will, and W. J. Norman. 2000. Citizenship in diverse societies: Issues, Contexts, Concepts. In Citizenship in diverse societies, edited by W. J. Norman and W. Kymlicka. Oxford ;New York: Oxford University Press.

Leith, J. Clark. 2005. Why Botswana prospered. Montreal: McGill-Queen's University Press.

Marope, P. T. M. 1996. The impact of educational policy reforms on the distribution of educational outcomes in developing countries: The case of Botswana. International Journal of Educational Development 16 (2):157-171.

Marshall, T. H. 2009 [1950]. Citizenship and Social Class. In Inequality and Society, edited by J. Manza and M. Sauder. New York: W.W. Norton and Co.

Meyer, John W., Joane Nagel, and Conrad W. Snyder, Jr. 1993. The Expansion of Mass Education in Botswana: Local and World Society Perspectives. Comparative Education Review 37 (4):454-475.

NCE. 1977. Kagisano ka Thuto: Education for Kagisano, Report of the National Commission on Education. Gaborone: Government of Botswana.

Repeated Author. 1993. Report of the National Commission on Education. Gaborone: Government of Botswana. 
Novelli, Mario, and Alan Smith. 2011. The Role of Education in Peacebuilding: A synthesis report of findings from Lebanon, Nepal and Sierra Leone. New York: UNICEF.

Nyamnjoh, Francis B. 2002. Local Attitudes towards Citizenship and Foreigners in Botswana: An Appraisal of Recent Press Stories. Journal of Southern African Studies 28 (4):755775.

Nyati-Ramahobo, Lydia. 2006. Language policy, cultural rights and the law in Botswana. Contributions to the Sociology of Language 92:285-304.

Repeated Author. 2006. The long road to multilingual schools in Botswana. In Imagining multilingual schools: Languages in education and glocalization, edited by O. Garcia, T. Skutnabb-Kangas and M. E. Torres-Guzman. Tonawanda, NY: Multilingual Matters, Ltd.

Nyati-Saleshando, Lydia. 2011. An Advocacy Project for Multicultural Education: The Case of the Shiyeyi Language in Botswana. International Review of Education 57 (5-6):567-582.

Osler, Audrey, and Kerry Vincent. 2002. Citizenship and the challenge of global education. Stoke on Trent, Staffordshire, England; Sterling, VA: Trentham Books.

Østby, Gudrun. 2008. Polarization, Horizontal Inequalities and Violent Civil Conflict. Journal of Peace Research 45 (2):143-162.

Pansiri, Nkobi Owen. 2012. Ethnocultural identities and school retention: The case of rural ethnic minorities in Botswana. AlterNative: An International Journal of Indigenous Peoples (8):3.

Paulson, Julia. 2015. "Whether and How?" History Education about Recent and Ongoing Conflict: A Review of Reseach. Journal on Education in Emergencies 1 (1):14-47.

Presidential Task Group for a Long-Term Vision for Botswana (PTG). 1997. Vision 2016: LongTerm Vision for Botswana, Towards Prosperity For all. Gaborone: Government Printing and Publishing Services.

Republic of Botswana. 1966. Constitution of Botswana. Gaborone.

Repeated Author. 1994. Junior Secondary School Syllabus for Social Studies, Form One and Two. Gaborone: Ministry of Education, Curriculum Development Unit.

Repeated Author. 1994. The Revised National Policy on Education. Gaborone: Republic of Botswana.

Repeated Author. 1996. Three-Year Junior Secondary Syllabus, Social Studies. Gaborone: Ministry of Education, Curriculum Development Unit.

Repeated Author. 2000. Report of the Presidential Commission of Inquiry into Sections 77, 78, and 79 of the Constitution of Botswana. Gaborone: Government Printer.

Repeated Author. 2001. National Policy on Culture. Gaborone: Ministry of Labour and Home Affairs, Department of Culture and Youth.

Repeated Author. 2009. National Development Plan 10 (2009-2016). Gaborone: Ministry of Finance and Development Planning.

Repeated Author. 2010. Three-Year Junior Secondary Syllabus. Gaborone: Ministry of Education, Curriculum Development Division.

Shields, Robin, and Julia Paulson. 2014. 'Development in reverse'? A longitudinal analysis of armed conflict, fragility and school enrolment. Comparative Education:1-19.

Smith, Anthony D. 1991. National identity, Ethnonationalism in comparative perspective. Reno: University of Nevada Press.

Tabulawa, Richard. 2009. Education reform in Botswana: Reflections on policy contradictions and paradoxes. Comparative Education 45 (1):87-107. 
Repeated Author. 2011. The rise and attenuation of the basic education programme (BEP) in Botswana: A global-local dialectic approach. International Journal of Educational Development 31 (5):433-442.

Tafa, Elmon M. 2004. Teacher socialisation; a critical qualitative analysis of the teaching methods of seven new teachers in Botswana junior secondary schools. International Journal of Educational Development 24 (6):757-758.

Turner, J.C., M.A. Hogg, P.J. Oakes, S.D. Reicher, and M.S. Wetherell. 1987. Rediscovering the social group: A self-categorization theory. Oxford: Basil Blackwell.

UNESCO. 2011. Education for All Global Monitoring Report 2011: The hidden crisis: Armed conflict and education. Paris: UNESCO.

Werbner, Richard. 2002. Challenging Minorities, Difference and Tribal Citizenship in Botswana. Journal of Southern African Studies 28 (4):671-684.

World Bank. 2015. Government expenditure on education, total (\% of GDP). Washington, DC. 


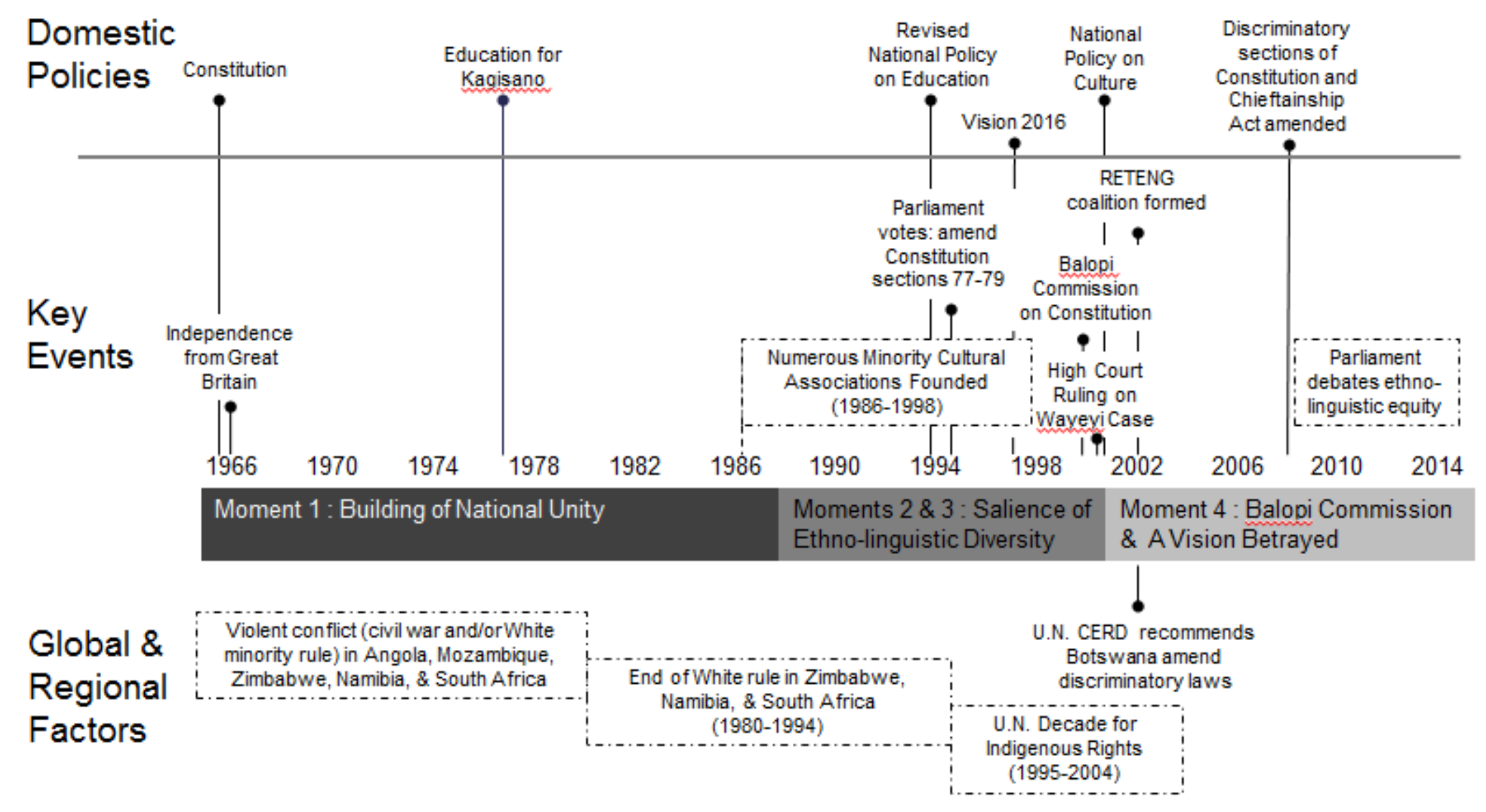

Figure 1. Negotiating national unity and ethnic diversity: Key moments in Botswana's post-independence education 